\title{
CONHECIMENTO TRADICIONAL ASSOCIADO AO USO DE BUTIÁS (Butia spp., ARECACEAE) NO SUL DO BRASIL ${ }^{1}$
}

\author{
MIRIAM VALLI BÜTTOW ${ }^{2}$, ROSA LÍA BARBIERI ${ }^{3}$, \\ RAQUEL SILVIANA NEITZKE ${ }^{4}$, GUSTAVO HEIDEN ${ }^{5}$
}

RESUMO - O gênero Butia é amplamente distribuído no Estado do Rio Grande do Sul e constitui parte importante da biodiversidade deste Estado. Devido à sua importância, foi realizado um levantamento do conhecimento tradicional associado a esta palmeira, enfocando principalmente os usos dados à planta e aos frutos. Para tanto, foram realizadas entrevistas em comunidades do interior de sete municípios do sul do Rio Grande do Sul. Entre os usos principais do butiá relacionados pelos entrevistados, destacam-se o consumo do fruto in natura, a produção de sucos, licores, geleias, sorvetes, bolos e bombons, além de outras sobremesas. Existem agroindústrias produzindo suco natural de butiá como uma nova alternativa para incrementar a renda familiar. Com as folhas e a polpa do fruto são realizados trabalhos artesanais, que são expostos em feiras. Esta planta é usada para ornamentar jardins e quintais. Os entrevistados reconhecem grande variabilidade entre os frutos do butiazeiro em relação ao tamanho, ao sabor, à coloração da película, à deiscência e à acidez. Também relatam a intensa interação de pássaros e insetos com a planta, especialmente nos períodos de floração e de frutificação. Além da manutenção do uso tradicional da planta pela população, produtos inovadores a partir do butiá vêm sendo desenvolvidos. Existe um grande potencial de utilização da planta de butiá, principalmente do fruto, na culinária, na produção de doces, geleias, suco e licor. As comunidades visitadas demonstram uma relação de afeto e respeito pelo butiazeiro.

Termos para indexação: etnobotânica, butiazeiros, uso tradicional.

\section{TRADITIONAL KNOWLEDGE ASSOCIATED WITH THE USE OF BUTIA PALM (Butia spp., Arecaceae) IN THE SOUTHERN OF BRAZIL}

\begin{abstract}
The Butia genus is widely distributed in the state of Rio Grande do Sul and it is established as an important part of this biodiversity. Due to its importance, a survey of traditional knowledge about this palm was conducted, focusing on uses of the plant and fruits. For this research, interviews were realized in rural communities of seven counties in the south of Rio Grande do Sul. Among the main uses of the butia palm related by the interviewers, the consumption of the fruit in natura, the juice production, liquors, jams, ice creams, cakes, candies and other desserts stand out. There are agro-industries producing natural butia palm juice as a new alternative to supplement the family income. Handicrafts are made with leaves and fruit pulp and sold in local fairs. This plant is also used as an ornamental in gardens and backyards. The interviewers recognize great variability among Butia fruits in terms of size, flavor, skin coloring, dehiscence and acidity. They report the intense interaction of birds and insects with the plant especially in the flowering and fruiting period. Along with the maintenance of the traditional uses of the plant by the population, innovative products from butia palm are being developed. There is a considerable potential to expand the uses of the Butia plant, mainly in cooking, sweet production, jam, juice and liquor. The visited communities showed a relationship of affection and respect for the Butia palms.
\end{abstract}

Index terms: ethnobotany, butia palm, traditional uses.

${ }^{1}$ (Trabalho 269-08). Recebido em: 31-10-2008. Aceito para publicação em: 21-07-2009.

${ }^{2}$ Doutoranda em Genética e Biologia Molecular, UFRGS. UFRGS - Campus do Vale - Avenida Bento Gonçalves, 9500 , Prédio 43323 M, CEP: 91501-970 Cx. Postal 15053 - Porto Alegre-RS. miriamvb@gmail.com

${ }^{3}$ Dr $^{\mathrm{a}}$. Pesquisadora da Embrapa Clima Temperado. Embrapa Clima Temperado, BR 392, Km 78, Cx. Postal 403, CEP 96001-970, Pelotas-RS. lia.barbieri@gmail.com

${ }^{4}$ Doutoranda em Agronomia, Área de Concentração Fitomelhoramento, UFPel. FAEM - Fitotecnia - Cx Postal 354, CEP 91501-970, Capão do Leão-RS. raquelsilviana@gmail.com

${ }^{5}$ M. Sc., Pesquisador Visitante da Embrapa Clima Temperado. Embrapa Clima Temperado, BR 392, Km 78, Cx. Postal 403, CEP 96001-970, Pelotas-RS. gustavo.heiden@gmail.com 


\section{INTRODUÇÃO}

Uma das famílias de plantas mais utilizadas pelos seres humanos em todo o mundo é a família Arecaceae (Palmae). Um elevado número de espécies possui importância econômica e ornamental (Jones, 1994; Galeano et al., 1995; Marcato, 2004). Os frutos das palmeiras fazem parte da dieta de animais silvestres frugívoros, como canídeos, roedores e psitacídeos (Galetti et al., 2003). Esta família abrange entre 2.500 e 3.500 espécies com distribuição pan-tropical e algumas espécies adaptadas a climas mais frios (Uhl \& Dransfield, 1987). No Rio Grande do Sul, é registrada a ocorrência de Butia capitata Becc., $B$. eriospatha Becc., B. odorata Becc., B. paraguayensis L. H. Bailey e B. yatay Becc. (Rossato, 2007). Estas espécies são conhecidas popularmente como butiá ou butiazeiros e seus frutos são popularmente denominados de butiá ou coquinho.

No entanto, algumas espécies de Butia já são consideradas em risco de extinção no Rio Grande do Sul (Rossato, 2007). A monocultura, a criação extensiva de gado e a especulação imobiliária são responsáveis por grande parte da redução das populações naturais de butiá (Azambuja, 1978; Rivas \& Barilani, 2004; Rivas, 2005; Rossato, 2007; Rossato \& Barbieri, 2007). Consequentemente, o conhecimento e as tradições relacionadas à planta são também perdidos.

Atualmente, existe interesse crescente em integrar a proteção da diversidade biológica, os costumes de sociedades tradicionais e a agricultura tradicional (Primack \& Rodrigues, 2002). No caso do butiá, Rivas (2005) sugere a criação de planos de desenvolvimento e promoção dos produtos derivados do butiazeiro, defendendo que o uso do butiá por moradores locais deve ser parte de uma estratégia de conservação da biodiversidade.

Neste contexto, a etnobotânica, ou seja, o estudo das interações entre pessoas e plantas, contribui para resgatar o conhecimento tradicional que pode estar em processo de se perder pelo choque com a cultura dominante, e também para resgatar os próprios valores das culturas com que entra em contato (Martin, 1995; Albuquerque, 2005).

O objetivo deste trabalho, portanto, é resgatar o conhecimento tradicional existente na região sul do Rio Grande do Sul a respeito da palmeira de butiá. O principal enfoque foi dado aos usos da planta, dos frutos, do estipe e da folha, assim como informações referentes à origem, à história, ao cultivo e ao manejo, de forma a servir de base a futuros programas de conservação, manejo e aproveitamento sustentável deste recurso genético.

\section{MATERIAL E MÉTODOS}

O levantamento etnobotânico realizado em comunidades do interior dos municípios de Arroio do Padre, Morro Redondo, Pelotas, Rio Grande, Santa Vitória do Palmar, São Lourenço do Sul e Turuçu, no Estado do Rio Grande do Sul (Figura 1). Os locais selecionados foram escolhidos a partir de informações prévias sobre a ocorrência de plantas do gênero Butia, e através de indicação dos próprios entrevistados, de acordo com o método bola-de-neve descrito por Albuquerque (2004). Para as entrevistas, foram escolhidas propriedades que tivessem, no mínimo, um butiazeiro.

Foram realizadas entrevistas semiestruturadas (Cervo \& Bervian, 1996). Neste tipo de entrevista, os entrevistados respondem a uma série de perguntas gerais preparadas anteriormente e outras que surgem naturalmente durante o transcurso da conversação (Martin, 1995). Inicialmente, foi explicado ao entrevistado o objetivo do trabalho e coletados os dados de identificação (nome, idade, profissão e sexo). A seguir, foram feitas perguntas a respeito da origem, usos, cultivo e manejo da planta. Para o levantamento etnobotânico, foram realizadas 35 entrevistas nos sete municípios selecionados. Foram entrevistadas pessoas de níveis socioculturais e atividades ocupacionais distintas: produtores rurais familiares, donas de casa e proprietários de agroindústrias familiares, um professor, um engenheiro agrônomo, um motorista, um doceiro, um pescador e uma empresária, com idades variando de 28 a 81 anos.

\section{RESULTADOS E DISCUSSÃO}

Principais usos: A parte da planta mais utilizada, segundo os entrevistados, é o fruto, para o consumo in natura, no preparo de licor, cachaça de butiá, suco, geleia, bolo, bombom, recheio do doce denominado "panelinha" e em sobremesas como sorvete, mousse e arroz de butiá. O consumo do fruto e o preparo de licor são conhecidos por todos os entrevistados, sendo que dois deles não apreciam o fruto devido à acidez e ao aroma, conservando o butiazeiro em suas propriedades devido ao seu caráter ornamental.

O preparo do licor de butiá, ou butiá na cachaça, foi citado em praticamente todas as propriedades. O modo de preparo do licor é variado. Em geral, é feito com uma medida de frutos e uma medida de cachaça ou vodka, permanecendo de três dias até um ano "curtindo". Alguns entrevistados acrescen- 
tam açúcar, mel ou uma calda preparada com água e açúcar. No município de Pelotas, foram registradas a produção artesanal e a comercialização de licor, como atrativos do turismo rural. Foi mencionada também uma maneira de fazer "caipira de butiá”, batendo a polpa do fruto no liquidificador, adicionando gelo, açúcar e cachaça ou vodka. O hábito de utilizar os frutos desta maneira também foi observado por Marcato (2004), no Paraná, por moradores de quase todas as localidades visitadas.

Das 35 pessoas entrevistadas, 20 citaram o preparo de suco como uma das principais utilizações. Entre os produtores rurais, é comum congelar o suco concentrado e armazená-lo em pequenas porções. Dessa maneira, o suco pode ser consumido durante o ano inteiro, até a safra seguinte. Aproximadamente a metade dos entrevistados considera importante selecionar frutos doces e pouco fibrosos para a fabricação de sucos, enquanto os demais não fazem essa distinção.

Duas agroindústrias (Figueira do Prado e Fazenda Boa Vista), no município de São Lourenço do Sul, preparam o suco de butiá concentrado. O método utilizado é o arraste a vapor, dispensando a adição de conservantes. Os frutos utilizados no preparo dos sucos são obtidos através de extrativismo nos locais de ocorrência, de doações e comercialização feitas por moradores vizinhos das propriedades. A principal diferença entre as duas agroindústrias é que uma utiliza o fruto inteiro e a outra retira o caroço antes de preparar o suco. Segundo observações empíricas feitas por uma das produtoras, o consumidor prefere o suco que é feito com o fruto inteiro, incluindo o caroço, pois considera que o método de arraste a vapor possibilita que o sabor do fruto seja acentuado devido à presença do caroço. Os proprietários das agroindústrias afirmam que o suco de butiá é um dos mais procurados pelo público, inclusive por frequentadores de academias de ginástica, que o consideram energético, a exemplo de frutos de outras palmeiras, como o açaí (Euterpe oleracea Mart.). A produção de suco fica restrita à época da safra do butiá.

Devido à variabilidade genética, são encontrados frutos cuja cor da película externa varia desde amarela até vermelha, o que resulta em diferentes colorações de suco. Este exemplo de utilização da biodiversidade na produção de sucos, além de considerar o ambiente onde está inserida, por utilizar uma planta nativa, exerce um papel importante para o estabelecimento de novas cadeias produtivas para o agronegócio da região e do País (Vilela-Morales \& Valois, 2000).

A amêndoa do butiá também é utilizada como alimento. Entre os entrevistados mais idosos, foi unânime o relato do consumo da amêndoa durante a infância, prática que não é mais realizada atualmente por eles. Na Ilha dos Marinheiros, em Rio Grande, foi relatado o preparo de licor e de rapadura a partir da amêndoa do butiá.

Dois entrevistados, uma dona de casa e um professor contam que tinham o hábito, quando crianças, de juntar uma grande quantidade de coquinhos e colocá-los próximos aos formigueiros para que as formigas os limpassem. Quando os coquinhos estivessem limpos, a amêndoa era separada e torrada no forno. A senhora contou que parte da brincadeira de "casinha" das meninas da estância era fazer um doce, cozinhando a amêndoa com açúcar. Este doce podia ser feito também com o coquinho do jerivá (Syagrus romanzoffianna Glass.). Estes coquinhos eram usados para jogar "bolinha de gude", segundo um entrevistado, em uma época em que as crianças não tinham como comprar brinquedos.

$\mathrm{O}$ artesanato a partir do butiazeiro foi relatado pelos entrevistados no município de Santa Vitória do Palmar, região de ocorrência natural de B. capitata. Os artesãos utilizam a polpa seca do fruto em um processo semelhante ao utilizado na fabricação de papel reciclado e, assim, obtêm papel de polpa de butiá. A partir das folhas são confeccionados cestos e porta-objetos. A produção de artesanato é atrativa como uma fonte alternativa de renda da população. No ano de 2007, nesse município, foi realizada a Primeira Feira do Butiá (Febutiá), que teve como objetivo apresentar produtos feitos com o fruto do butiazeiro e o artesanato produzido com as folhas e com a polpa do fruto. Rossato \& Barbieri (2007) relatam que os indígenas já utilizavam as folhas do butiá para a confecção de cestas, chapéus, bolsas, redes, armadilhas para caça e pesca, e como cobertura de suas habitações.

O caráter ornamental da planta foi fortemente evidenciado durante a realização deste trabalho. A presença dos butiazeiros sempre próximos da casa, com o cultivo de outras plantas ornamentais (orquídeas, cactos, bromélias, samambaias) no estipe, é comum nos municípios de Arroio do Padre, Rio Grande, Santa Vitória do Palmar, São Lourenço do Sul e Turuçu. Reitz (1974) relata que butiazeiros cultivados podiam ser observados frequentemente em jardins e praças, em virtude do belo aspecto e vistosas inflorescências, sobretudo nas cidades próximas ao litoral de Santa Catarina. Nas regiões do Paraná, visitadas por Marcato (2004), foi observada a presença de butiazeiros em jardins particulares. Este autor constatou que mudas de butiá são levadas da região de ocorrência natural para serem vendidas em outras regiões. Tal prática representa uma séria 
ameaça às populações nativas de B. eriospatha, devido ao grande tempo de desenvolvimento requerido para que esta palmeira de campo atinja sua maior estatura. Da mesma forma, Rossato \& Barbieri (2007) relataram que, no Rio Grande do Sul, mudas de espécies de palmeiras dos gêneros Trithrinax, Geonoma, Bactris, Syagrus, Butia e Euterpe são retiradas de seu habitat para serem comercializadas. $\mathrm{O}$ extrativismo ilegal dessas palmeiras demonstra que há um potencial comercial inexplorado de produção e comercialização de mudas de palmeiras nativas.

Um dos entrevistados de Santa Vitória do Palmar relatou a exploração comercial da folha seca dos butiazeiros, chamada crina vegetal, que ocorreu na década de 1930. A crina vegetal era usada para a confecção de colchões, por uma indústria que se instalou na região, mas que não conseguiu estabelecer-se por mais tempo devido às dificuldades encontradas, sobretudo pela presença de espécies de serpentes peçonhentas nos butiazais de onde era extraída a crina vegetal. De acordo com Marcato (2004), moradores do Paraná também relataram que os folíolos do butiazeiro eram utilizados no passado para a confecção de enchimento para colchões, porém esta prática não é mais utilizada. No município de Santa Vitória do Palmar, os entrevistados relataram que grande parte dos palmares nativos foi destruída para dar lugar à monocultura ou a pastagens para o gado, sofrendo com a exploração extrativista. Esta situação foi também encontrada por Rossato \& Barbieri (2007) em outras regiões do Rio Grande do Sul.

Manejo da planta: Uma das grandes dificuldades do aproveitamento do butiá está no longo período que a semente leva para germinar, chegando até 24 meses, além do longo período até a frutificação (Carpenter, 1988; Broschat, 1998). Segundo os entrevistados, algumas plantas levaram 10 anos para começar a produzir frutos. Dois entrevistados, um de Rio Grande e outro de Pelotas, relataram que, quando a muda de butiazeiro é transplantada, a produção de frutos começa no terceiro ou quarto ano de vida da planta. Os produtores das agroindústrias e um produtor de Rio Grande relataram que as sementes colocadas em um minhocário durante cerca de dois meses germinaram logo após serem retiradas.

Em todos os locais, os entrevistados informaram que o butiazeiro produz frutos uma vez ao ano, florescendo de outubro a dezembro e frutificando de janeiro a abril. Existem raros casos de florescimento no mês de junho e frutificação em julho.

Em duas entrevistas, uma em São Lourenço do Sul e outra em Turuçu, os entrevistados estabeleceram uma relação direta entre a poda de folhas secas e a produtividade da planta. Segundo os entrevistados, as plantas que são podadas após a frutificação produzem mais cachos e mais frutos na próxima safra.

Em entrevistas realizadas no município de Turuçu, e em algumas de Santa Vitória do Palmar e de São Lourenço do Sul, foi constatado o costume de proteger o cacho ainda verde com um saco, de modo a evitar a presença de abelhas, moscas e outros insetos, além de evitar a queda dos frutos. Alternativamente, o cacho pode ser colhido ainda verde e guardado até a sua maturação. Esta prática utilizada pela população está de acordo com o trabalho de Neuwald et al. (2004), que classifica o butiá como um fruto climatérico, isto é, apresenta picos de produção de etileno e de respiração seguidos pelo processo de maturação de consumo. Segundo os relatos dos entrevistados em São Lourenço, Turuçu e Santa Vitória do Palmar, a colheita antes da maturação evita ainda um incômodo bastante comum, que é o roubo de cachos maduros.

Quando perguntados sobre a variabilidade existente entre tipos de fruto de butiá, os entrevistados mencionaram inicialmente o butiá-amarelo e, em seguida, diversas tonalidades de laranja e vermelho, até o vermelho intenso. Também foi relatada a existência do butiá-branco. Existem ainda diversos tamanhos de fruto, diferenças quanto à maior ou menor presença de fibras e maior ou menor acidez. Há ainda frutos de polpa presa ao coquinho e frutos de polpa solta (molares). Os entrevistados relataram que alguns cachos debulham quando maduros e outros não. Enquanto a maioria dos entrevistados distinguia os butiazeiros em apenas duas categorias, "butiá-amarelo" e "butiá-vermelho”, ou “doce” e “azedo”, “pequeno” e "grande”, um agricultor de São Lourenço do Sul afirmou: "Existem mais de cinquenta tipos de butiá!”. De acordo com De Paula et al. (2006), a variação genética é também percebida por extrativistas de Minas Gerais, que distinguem duas variações principais do que chamam de coquinho-azedo (Butia capitata): um tipo mais redondo, casca lisa e polpa adocicada, e outro alongado, casca enrugada e polpa mais ácida. Também podem ser observados frutos de coloração avermelhada, os quais ocorrem com menor frequência do que os amarelos.

Os frutos dos butiazeiros são intensamente visitados por insetos, como moscas e abelhas (Rossato, 2007). Em Santa Vitória do Palmar, um entrevistado declarou que a melhor forma de aproveitar os frutos é deixando-os de molho na água por determinado período para que os insetos se afastem. Segundo seu relato, o melhor fruto, por ser mais doce e estar livre dos insetos, é o do último cacho 
produzido pela planta, o qual geralmente amadurece no mês de abril, um mês mais frio e que desfavorece a proliferação dos insetos.

Os entrevistados de São Lourenço do Sul e Santa Vitória do Palmar discordam quanto à qualidade do solo onde o butiazeiro está presente. No primeiro município, uma entrevistada disse que o butiá era indicador de terras ruins, pois onde ele nasce poucos tipos de plantas se desenvolvem. Por outro lado, em Santa Vitória do Palmar, foi relatado que onde existe butiá o solo é fértil, uma vez que a planta nasce e cresce espontaneamente, sem necessitar de cuidados especiais.

Uma crença popular surge a partir do fato de que é muito comum encontrar mudas de figueiras (Ficus cestrifolia Schott.) sobre a palmeira de butiá.
Uma entrevistada acredita que quando a palmeira serve de suporte para a figueira, o butiá fica mais doce, devido ao sabor doce do figo. Martin (1995) afirma que este tipo de explicação a respeito de fenômenos naturais e práticas culturais são constantes em levantamentos etnobotânicos.

Durante o trabalho, foi evidenciado que o conhecimento tradicional relacionado ao uso da planta e do fruto do butiazeiro pela população do sul do Rio Grande do Sul tem sido explorado de várias formas. Alguns usos tradicionais são plenamente difundidos na cultura da região, como a produção de licor em todos os municípios abrangidos pelo levantamento. Em alguns lugares, novos hábitos e novas formas de aproveitar o fruto e a planta são constantemente criados e modificados, como, por exemplo, a produção de doces e de papel reciclado com a polpa do fruto.

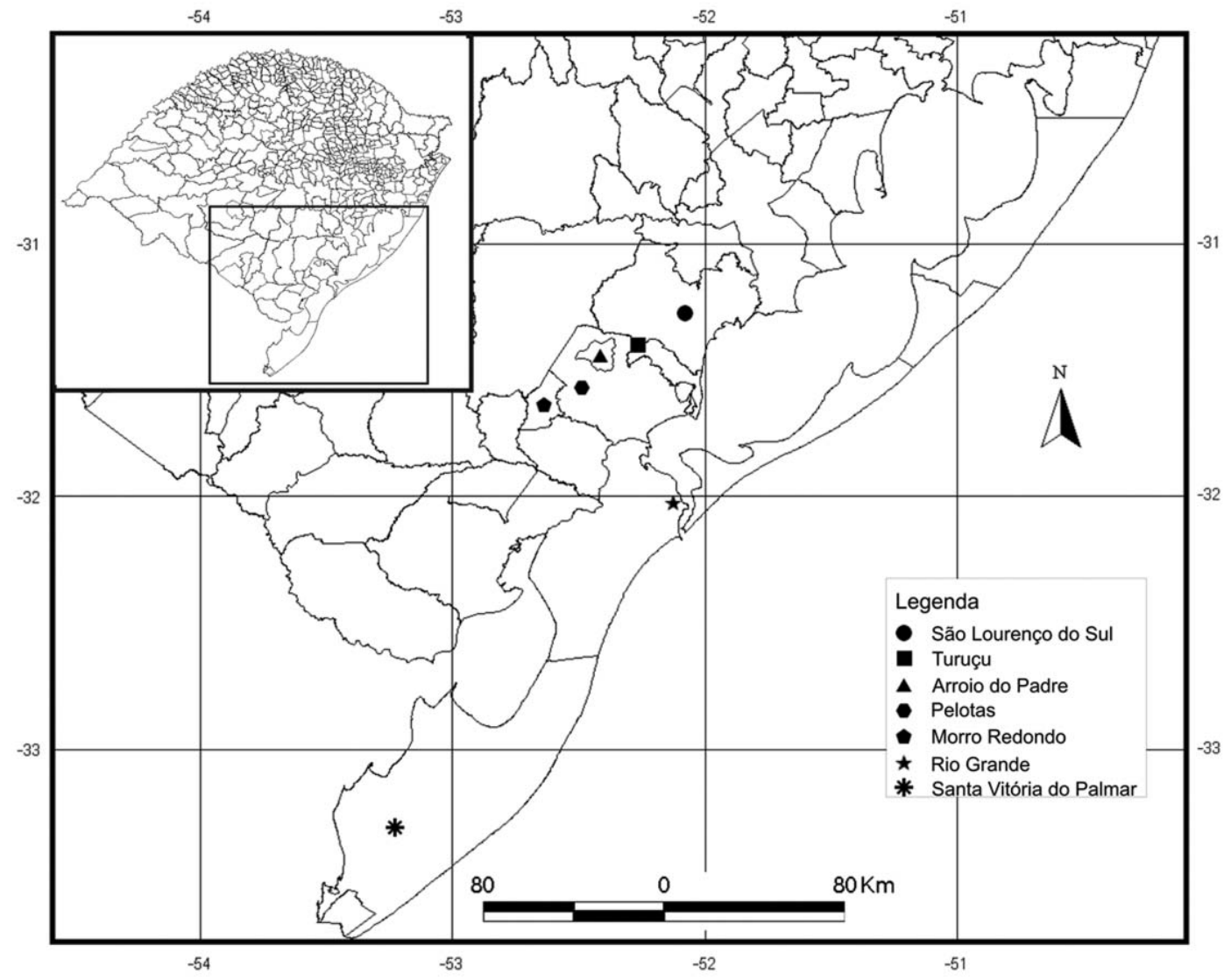

FIGURA 1 - Mapa do Rio Grande do Sul mostrando os locais de realização das entrevistas para o levantamento etnobotânico. 


\section{CONCLUSÕES}

1-O levantamento etnobotânico realizado evidencia que a relação do ser humano com o butiá é estabelecida desde a infância. Há uma relação de afeto e respeito ao butiazeiro nas comunidades visitadas. A produção de sucos e licores é comum em alguns locais como fonte de renda para a população, e esta alternativa tende a ampliar-se com o desenvolvimento de novos produtos a partir dos frutos e do artesanato das folhas desta palmeira.

2-Além do aproveitamento da planta, os entrevistados forneceram dados empíricos sobre aspectos do manejo, como germinação, poda, transplante e produtividade.

\section{AGRADECIMENTOS}

Os autores agradecem ao CNPq, pela concessão de bolsa de Mestrado, à CAPES, à FAPERGS e ao projeto CT Agronegócio 04/2006 CNPq/ FAPERGS.

\section{REFERÊNCIAS}

ALBUQUERQUE, U. P. Introdução à etmobotânica. 2.ed. Rio de Janeiro: Interciência, 2005. 80p.

ALBUQUERQUE, U. P. Métodos e técnicas na pesquisa etnobotânica. Recife: Livro Rápido/NEPEEAT, 2004. 189p.

AZAMBUJA, P. Tahim a última divisa: geografia e história de uma região. Santa Vitória do Palmar: Polygraph \& Stillus Artes Gráficas, 1978. 251p.

BROSCHAT, T.K. Endocarp removal enhances Butia capitata (Mart.) Becc. (Pindo Palm) seed germination. HortTechnology, Alexandria, v.8, n.4, p.586-587, 1998.

CARPENTER, W.J. Seed after ripening and temperature influence in Butia capitata germination. HortScience, Alexandria, v.23, n.4, p.702-703, 1988.

CERVO, A.L.; BERVIAN, P.A. Metodologia científica. 4. ed. São Paulo: Makron Books, 1996. 209p.
DE PAULA, T.O.M.; SANTOS, A.M.; GUILHERME, D.O.; CALDEIRA JUNIOR, C.F.; ARAÚJO, C.B.; GONÇALVES, W.S.; MARTINS, E.R.; LOPES, P.S.N. Ecogeografia e etnobotânica do coquinho-azedo no norte de Minas Gerais. In: CONGRESSO BRASILEIRO DE FRUTICULTURA, 19. 2006, Cabo Frio. Palestras e resumos... Cabo Frio: SBF/UENF/Universidade Federal Rural do Rio de Janeiro, 2006. p. 271.

GALEANO, G.; BERNAL, R.; HENDERSON, A. Field guide to the palms of the Americas. Princeton: Princeton University Press, 1995. 363 p.

GALETTI, M.; PIZO, M. A.; MORELLATO, P. Fenologia, frugivoria e dispersão de sementes. In: CULLEN Jr, L.; RUDRAN R.; VALLADARESPADUA, C. Métodos de estudos em biologia da conservação e manejo da vida silvestre. Curitiba: Editora UFPR, 2003. p.395-422.

JONES, D.L. Palms throughout the world. Washington: The Smithsonian Institution Press, 1994. 410p.

MARCATO, A.C. Revisão taxonômica do gênero Butia (Becc.) Becc. (Palmae) e filogenia da subtribo Buttiinae Saakov (Palmae). 2004. 147f. Tese (Doutorado em Ciências) - Universidade de São Paulo, São Paulo, 2004.

MARTIN, G.J. Etnobotânica: “pueblos y plantas” manual de conservacion. Montevideo: NordanComunidad, 1995. 240p.

NEUWALD, D.A.; GIEHL, R.F.H.; PINTO, J.A.V.; SESTARI, I.; BRACKMANN, A. Caracterização das curvas de respiração e síntese de etileno de frutos de Psidium cattleianum Sabine e de Butia capitata (Mart.) Becc. In: SIMPÓSIO NACIONAL DO MORANGO, 2.; ENCONTRO DE PEQUENAS FRUTAS E FRUTAS NATIVAS DO MERCOSUL, 1. 2004, Pelotas. Anais... Pelotas: EMBRAPA, 2004.

PRIMACK, R.; RODRIGUES, E. Biologia da conservação. Londrina: Planta, 2002. 327p.

REITZ, R. Palmeiras. In: Flora ilustrada catarinense. Itajaí: Herbário Barbosa Rodrigues, 1974. 189p. 
RIVAS, M. Desafios y alternativas para la conservación in situ de los palmares de Butia capitata (Mart.) Becc. Agrociencia, Montevideo, v. 9, n.2, p.161-168, 2005.

RIVAS, M.; BARILANI, A. Diversidad, potencial productivo y reproductivo de los palmares de Butia capitata (Mart.) Becc. de Uruguay. Agrociencia, Montevideo, v.8, n.1, p.11-21, 2004.

ROSSATO, M. Recursos genéticos de palmeiras nativas do gênero Butia do Rio Grande do Sul. 2007. 136 f. Tese (Doutorado em Agronomia) Universidade Federal de Pelotas, Pelotas, 2007.
ROSSATO, M.; BARBIERI, R.L. Estudo etnobotânico de palmeiras do Rio Grande do Sul. Revista Brasileira de Agroecologia, Porto Alegre, v. 2, n. 1, p.997-1000, 2007.

UHL N. W. DRANSIFIELD, J. Genera palmarum: a classification of Palms based on the work of Harald E. Moore, Jr. Lawrecen: Allen Press,1987. 610p.

VILELA-MORALES, E.A.; VALOIS, A.C.C. Recursos genéticos vegetais autóctones e seus usos no desenvolvimento sustentável. Cadernos de Ciência \& Tecnologia, Brasília, v.17, n.2, p.11-42, 2000. 